\title{
Aplikasi Absensi Dosen pada Kegiatan Belajar Mengajar dengan Menggunakan QR Code Di Gedung AH Prodi JTD Politeknik Negeri Malang
}

\author{
Debby Muliawati Gutama1, Mochammad Junus², Putri Elfa Mas'udia ${ }^{3}$ \\ 1,2 Program Studi Jaringan Telekomunikasi Digital, \\ Jurusan Teknik Elektro, Politeknik Negeri Malang, Indonesia \\ 3 Program Studi Teknik Telekomunikasi, \\ Jurusan Teknik Elektro, Politeknik Negeri Malang, Indonesia
}

1'gutamadebby@gmail.com, ${ }^{2}$ mochammad.junus@polinema.ac.id, ${ }^{3}$ putri.elfa@polinema.ac.id

\begin{abstract}
Education today demands a better regular and scheduled level of discipline so that the teaching and learning process can take place according to a predetermined schedule. However, most education parties still experience difficulties in demanding this because attendance activities are still manual and less regular in monitoring. The purpose of this study is to assist lecturers in carrying out daily class attendance by utilizing QR Code as a differentiator, which makes it easier for them to use smartphones from each lecturer. In this research, a lecturer attendance application using QR-Code was made where lecturers can do attendance using a smartphone camera for scanning the QR-Code that has been provided in each classroom. From the results of tests carried out on the application made, it was found that the application runs smoothly on several versions of Android and smartphone brands but on Android version 6.0 there is a lack of appearance and when scanning QR-Code it takes time. When testing QoS, the highest delay value is in the 2nd Floor AH Building with a value of 120.1695 which means good and the average packet loss is $8 \%$, while for the highest throughput on the 2nd floor AH Building with an average value of 7.598487 which means speed good network.
\end{abstract}

Kata Kunci: Android, QR-Code, Attendance, APK, QoS

Abstrak- Dunia pendidikan saat ini menuntut tingkat kedisiplinan yang teratur dan terjadwal yang lebih baik agar proses belajar mengajar dapat berlangsung sesuai dengan jadwal yang sudah ditentukan. Tetapi kebanyakan pihak pendidikan masih mengalami kendala untuk menuntut hal tersebut dikarenakan kegiatan absensi yang masih manual dan kurang teratur dalam monitoringnya. Tujuan dari penelitian ini yaitu untuk membantu dosen dalam melakukan absensi kelas harian dengan memanfaatkan QR Code sebagai pembeda, yang mempermudah karena menggunakan smartphone dari masing-masing dosen. Pada penelitian ini dibuat sebuah aplikasi absensi dosen dengan menggunakan QR-Code dimana dosen dapat melakukan absensi dengan menggunakan kamera smartphone untuk scanning QR-Code yang telah disediakan di setiap ruang kelas. Dari hasil pengujian yang dilakukan terhadap aplikasi yang dibuat, didapatkan hasil bahwa aplikasi berjalan dengan lancar pada beberapa versi android dan merk smartphone namun pada android versi 6.0 terdapat kekurangan pada tampilannya dan saat scanning QR-Code memerlukan waktu. Saat pengujian QoS nilai delay tertinggi yaitu pada Gedung AH Lantai 2 dengan nilai 120,1695 yang berarti bagus dan rata-rata packet loss yaitu 8\%, sedangkan untuk throughput tertinggi pada Gedung AH lantai 2 dengan nilai rata-rata 7,598487 yang berarti kecepatan jaringan bagus.

Kata Kunci: Android, QR-Code, Absensi, APK, QoS

\section{PENDAHULUAN}

Dunia pendidikan saat ini tingkat kedisiplinan lebih diutamakan agar proses belajar mengajar dapat berlangsung sesuai dengan jadwal yang sudah ditentukan. Permasalahan yang sering timbul dalam Perguruan Tinggi saat ini adalah penggunaan absensi dan penginputan data absensi yang masih manual. Selain itu sistem absensi yang digunakan saat ini masih bersifat manual.[1]

Terdapat penelitian yang membahas tentang sebuah sistem yang membaca serta membuat laporan kehadiran dosen menggunakan kode QR [2]-[5]. Setiap dosen disediakan kartu yang memiliki kode QR yang berbeda satu dengan yang lainnya. Sistem ini menggunakan koordinat pengguna saat ini untuk mendapatkan garis lintang dan bujur untuk lokasi dan jika lokasi kehadirannya ditandai dalam $10 \mathrm{~m}$ yang di tentukan, maka kehadirannya akan dianggap sah dan sistem akan dianggap tidak sah jika pengguna tidak berada pada posisi yang di tentukan [2].

Berdasarkan permasalahan pada latar belakang di atas maka akan dibuat "Aplikasi absensi dosen pada kegiatan belajar mengajar dengan menggunakan QR-Code di Gedung AH Program Studi JTD Politeknik Negeri Malang”. Dengan menggunakan aplikasi ini pengguna dapat melakukan absensi melalui smartphone dengan cara login pada aplikasi absensi kemudian scan QR-Code yang telah disediakan diruang kelas. Setelah itu dosen mengisikan tema pada materi yang akan diajarkan [3]. Jika dosen tidak hadir karena sakit atau izin maka harus membuat surat izin kemudian mengunggahnya pada aplikasi. 


\section{METODE}

\section{A. Rancangan Penelitian}

Pada penelitian ini akan dibahas tentang perancangan sistem absensi dosen menggunakan QR-Code. Pada gambar 1 diperlihatkan rancangan penelitian yang dilakukan saat penelitian, tahapan pertama yaitu melakukan studi literatur mengenai absensi dosen dan pembuatan aplikasi, kebutuhan alat dan bahan yang digunakan dalam pembuatan perecanaan sistem, diantaranya mengenai jumlah pengunaan software yang dibutuhkan, cara penggunaan software, karateristik software.

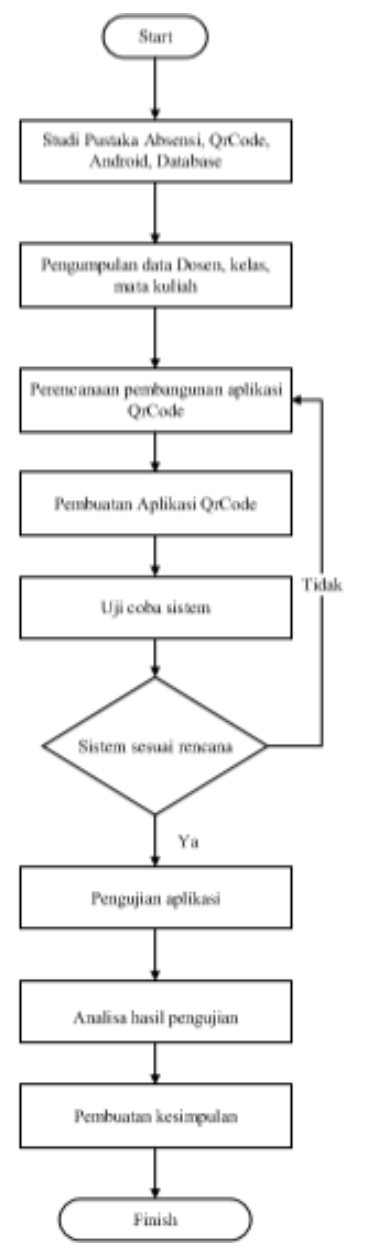

Gambar 1 Diagram Alir Tahapan Penelitian

Tahapan kedua yaitu perencanaan software sistem, dalam perencaan ini meliputi desain aplikasi, sistem output aplikasi dan perkiraan letak aplikasi yang diperlukan. Tahapan ketiga adalah perancangan aplikasi, pada tahapan ini dilakukan perancangan struktur dari sistem dan aplikasi yang akan dibangun. Tahapan keempat yaitu melakukan implemetasi aplikasi, implementasi aplikasi sesuai dengan rancangan sistem yang telah dibuat, pada penelitian ini diimplementasikan di Gedung AH JTD Polinema. Pada tahap kelima dilakukan pengujian aplikasi, meliputi pengujian program, pengujian keseluruhan aplikasi, dan pengujian penyimpanan pada form izin yang dilakukan dosen dan disimpan keserver.
Tahapan keenam yaitu analisa aplikasi, pada tahap ini dilakukan analisa sistem kerja diantaranya program dapat berjalan sesuai dengan sistem yang telah direncanakan, pengiriman data ke server, jika hasil sistem kerja yang diperoleh memenuhi sistem yang telah direncanakan maka dapat ditarik kesimpulan, apabila hasil sistem kerja yang diperoleh tidak memenuhi sistem yang telah direncanakan maka akan dilakukan pengecekan ulang pada software, perancangan aplikasi dan pengecekan pada pembuatan aplikasi yang telah dibuat. Tahapan terkahir yaitu pembuatan kesimpulan, pembuatan kesimpulan ini dapat dilakukan apabila hasil dari aplikasi telah sesuai dengan perancangan sistem yang telah dibuat.

\section{B. Blok Diagram Sistem}

Gambar 3.2 menjelaskan tentang diagram blok sistem pada penelitian yang dilakukan. Pengguna melakukan log in terlebih dahulu pada aplikasi agar bisa menscan QR-Code. Aplikasi terhubung dengan dengan jaringan lokal yang terdapat di Gedung AH. Setelah melakukan login pengguna melakukan scan Qr Code yang terdapat di setiap kelas untuk mengaktifkan absensi mahasiswa. Setelah pengguna melakukan scan, data tersebut akan tersimpan dalam database dan akan muncul notifikasi dan history dalam 1 hari.

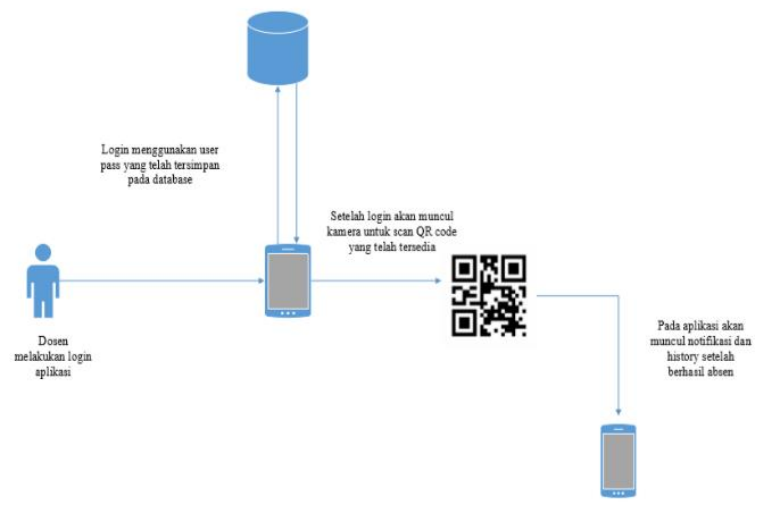

Gambar 2 Blok Diagram Sistem

\section{Data Flow Diagram}

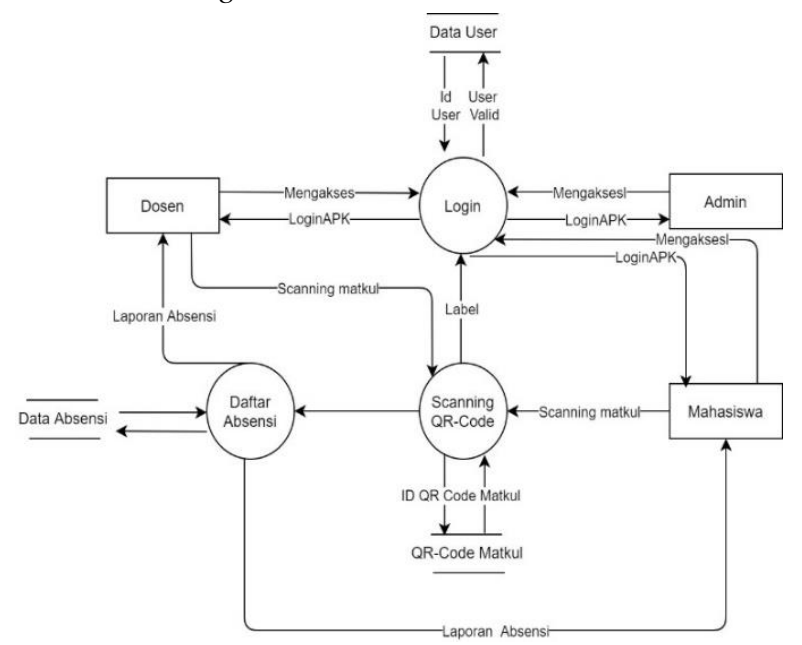

Gambar 3 Data Flow Diagram 
Berikut penjelasan pada Gambar 3:

1) Admin: Admin melakukan login ke aplikasi menggunakan hak akses admin lalu sistem mengecek data yang dimasukkan Admin. Kemudian jika data benar, Admin dapat login dan menggunakan fitur-fitur pada aplikasi seperti input data mahasiswa program studi jaringan telekomunikasi digital, kemudian data akan disimpan pada database db_absen. Selain menambahkan data, admin juga bisa mengubah data dan menghapus data yang sudah tidak digunakan lagi.

2) Mahasiswa: Mahasiswa melakukan login pada aplikasi dengan username dan password yang sudah ditentukan, kemudian mahasiswa akan melakukan scan qrcode untuk absensi, jika berhasil berhasil maka muncul pop up bahwa absensi sukses. Jika mahasiswa tersebut berhalangan untuk hadir dapat menggunakan fitur izin / sakit pada aplikasi. Kemudian jika mata kuliah telah berakhir user dapat melihat history absensi.

3) Dosen: Dosen melakukan login pada aplikasi dengan username dan password yang sudah ditentukan, kemudian dosen akan melakukan scan qrcode untuk absensi, jika dosen tersebut berhalangan untuk mengajar dapat menggunakan fitur izin pada aplikasi. Kemudian jika dosen telah selesai mengajar, dosen dapat melihat aktivitas hari ini dan melihat daftar mahasiswa yang masuk pada kelas tersebut dan memvalidasi jika ada mahasiswa yang izin.

\section{HASIL DAN PEMBAHASAN}

\section{A. Tampilan Aplikasi}

1) Prelogin: Halaman prelogin yang mana pengguna akan memilih login sebagai mahasiswa atau dosen.

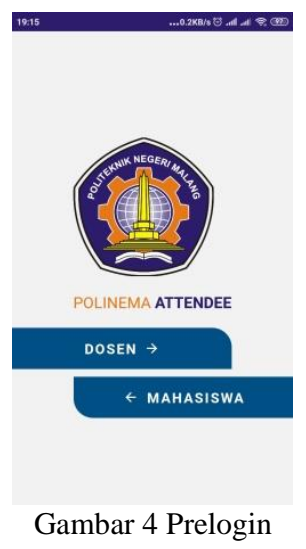

2) Login: Sebelum mengakses aplikasi, user diharuskan untuk login terlebih dahulu dengan mengisi NIP dan password yang telah ditentukan
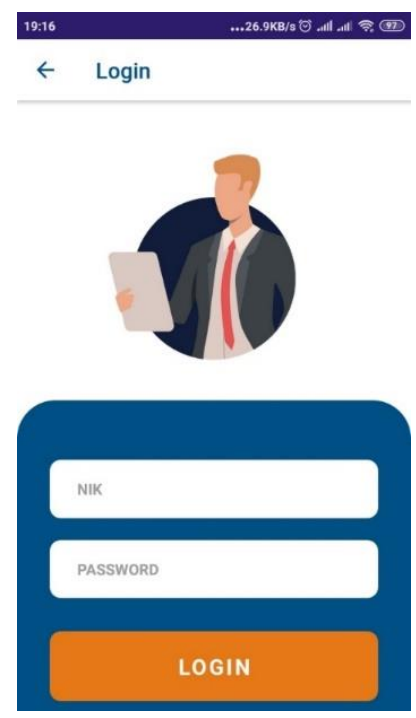

Gambar 5 Login

3) Absensi: Pada halaman absen setelah user berhasil login maka akan muncul halaman untuk menscan QR-Code yang telah disediakan. Jika berhasil maka akan muncul tampilan dengan status masuk.

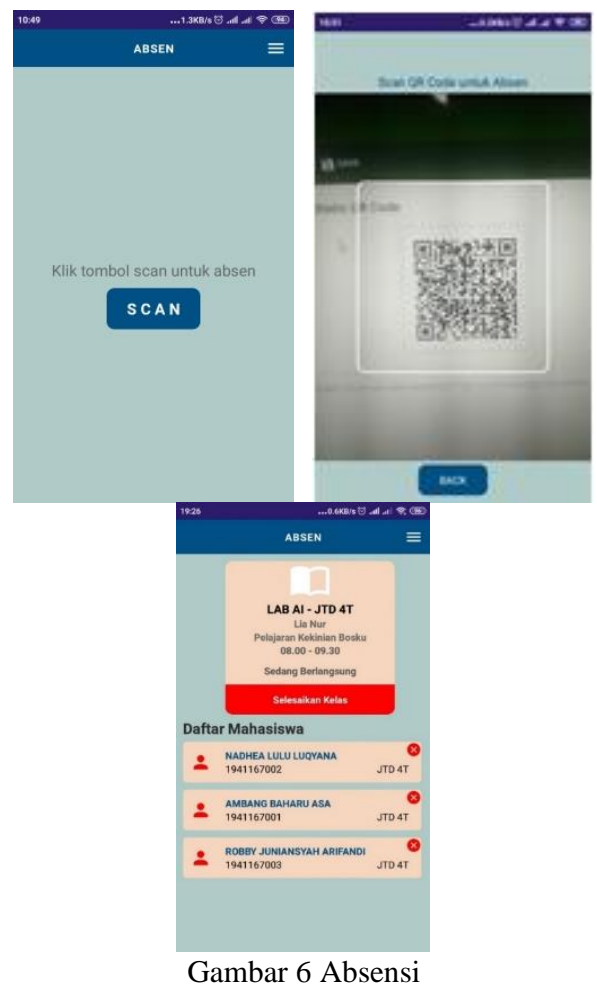

4) Permohonan Ijin: Pada halaman permohonan izin jika dosen berhalangan hadir maka dosen tersebut dapat mengunggah surat pada menu permohonan izin. 


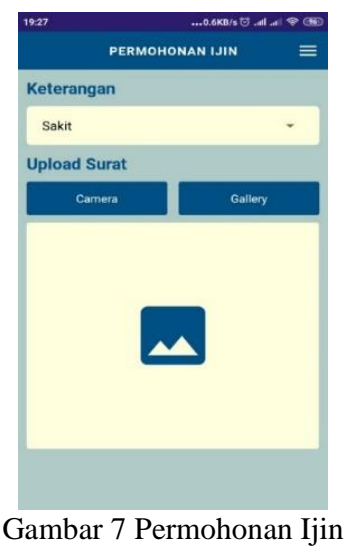

5) History: Pada halaman history yang berisi history absensi dosen pada hari tersebut.

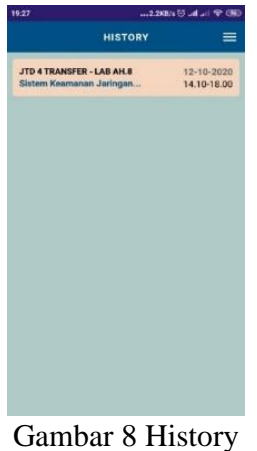

6) History Detail: Pada halaman tentang dimana berisi tentang riwayat absensi yang dilakukan dosen dan mahasiswa pada hari tersebut.

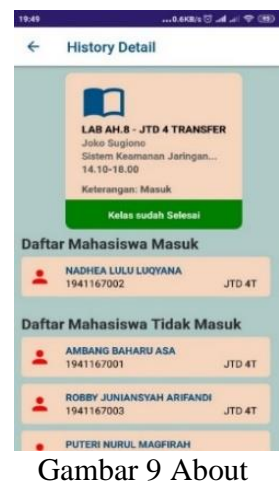

\section{B. Pengujian Installasi Aplikasi}

Pengujian installasi aplikasi dilakukan untuk memastikan bahwa instalasi dan fungsi pada aplikasi dapat berjalan sesuai tugasnya di beberapa merk smartphone dan versi android yang berbeda.

Dari percobaan yang telah dilakukan, dari 7 merk smartphone dan versi android yang berbeda semuanya berhasil melakukan penginstalan aplikasi dengan lancar dan aplikasi dapat digunakan.
TABEL I

PENGUJIAN INSTALLASI APLIKASI

\begin{tabular}{cllcc}
\hline No. & \multicolumn{1}{c}{ Nama User } & $\begin{array}{c}\text { Merk } \\
\text { Smartphone }\end{array}$ & $\begin{array}{c}\text { Versi } \\
\text { Android }\end{array}$ & $\begin{array}{c}\text { Fungsio } \\
\text { nal }\end{array}$ \\
\hline 1. & $\begin{array}{l}\text { Debby } \\
\text { Muliawati G }\end{array}$ & $\begin{array}{l}\text { Samsung } \\
\text { A50s } \\
\text { Samsung }\end{array}$ & 10.0 & OK \\
2. & $\begin{array}{l}\text { Intan } \\
\text { Retnoningtyas }\end{array}$ & $\begin{array}{l}\text { Galaxy A7 } \\
\text { Oppo }\end{array}$ & OK \\
3. & $\begin{array}{l}\text { Aditya Zaky } \\
\text { 4. }\end{array}$ & $\begin{array}{l}\text { Ade Kirana } \\
\text { Oppo A5 }\end{array}$ & $\begin{array}{l}\text { Op.0 } \\
\text { 2020 }\end{array}$ & OK \\
5. & $\begin{array}{l}\text { Azlamiy } \\
\text { Yzerino }\end{array}$ & $\begin{array}{l}\text { Redmi } 4 \mathrm{X} \\
\text { Yogananta gatot }\end{array}$ & 7.0 & OK \\
6. & Amin Rodhi A & Samsung & 9.0 & OK \\
7. & Putri Nurul M & $\begin{array}{l}\text { A20s } \\
\text { Redmi Note } 8\end{array}$ & 9.0 & OK \\
\hline
\end{tabular}

\section{Pengujian Delay}

Pengukuran delay digunakan untuk mengetahui waktu yang dibutuhkan data menempuh jarak dari source ke destination.

TABEL II

PenguJian Delay

\begin{tabular}{clccl}
\hline No & Lokasi & Delay(ms) & Indeks & Keterangan \\
\hline 1 & AH & 80,5981 & 4 & Sangat Bagus \\
& Lantai 1 & & & \\
2 & AH & 120,1695 & 3 & Bagus \\
& Lantai 2 & & & \\
3 & AH & 75,72319 & 4 & Sangat Bagus \\
& Lantai 3 & & & \\
\hline
\end{tabular}

Dari pengujian yang telah dilakukan, delay dengan nilai tertinggi berada di Gedung AH Lantai 2 dengan rata-rata delay $120,1695 \mathrm{~ms}$. Sedangkan nilai terendah berada di Gedung AH Lantai 3 dengan rata-rata delay 75,72319ms. Menurut standar TIPHON jika rata-rata delay > $450 \mathrm{~ms}$ masuk ke kategori Bagus. Artinya, waktu tunda suatu sistem untuk melewatkan sejumlah paket data lebih kecil sehingga kecepatan internet sangat lancar dan sinyal sangat stabil. Nilai delay dipengaruhi oleh besar paket dan lama waktu pengiriman, sehingga pada proses pengiriman data mengalami keterlambatan.

\section{Pengujian Packet Loss}

Packet Loss merupakan parameter untuk menggambarkan paket yang hilang, hal ini dapat dipengaruhi oleh congestion pada jaringan.

TABEL III

PENGUJIAN PACKET LOSS

\begin{tabular}{ccccc}
\hline No & Lokasi & Packet Loss & Indeks & Keterangan \\
\hline 1 & AH Lantai 1 & 9 & 3 & Bagus \\
2 & AH Lantai 2 & 8 & 3 & Bagus \\
3 & AH Lantai 3 & 8 & 3 & Bagus \\
\hline
\end{tabular}

Berdasarkan hasil pengujian diatas, dapat diketahui bahwa nilai packet loss paling besar yaitu $10 \%$ saat jumlah user 4 dan 6 mengakses aplikasi.Hasil rata-rata packet loss yang diperoleh 
dari pengujian ini memiliki nilai indeks 3 yang berarti bahwa degredasi bagus menurut THIPON.

\section{E. Pengujian Throughput}

Pengukuran troughput merupakan total kedatangan paket yang sukses yang diamati pada tujuan selama interval waktu tertentu dibagi oleh durasi interval waktu tersebut.

TABEL IV

PENGUJIAN THROUHPUT

\begin{tabular}{ccc}
\hline No & Lokasi & Throughput (kbps) \\
\hline 1 & AH Lantai 1 & 3,17709 \\
2 & AH Lantai 2 & 7,598487 \\
3 & AH Lantai 3 & 4,245783 \\
\hline
\end{tabular}

Berdasarkan hasil pengujian diatas, dapat diketahui bahwa hasil pengukuran throughput terendah pada pengujian 1 User yaitu sebesar $9,85472 \mathrm{bit} / \mathrm{s}$ dan tertinggi pada pengujian $7 \mathrm{User}$ yaitu sebesar $282,388 \mathrm{bit} / \mathrm{s}$.

\section{KESIMPULAN}

Aplikasi absensi dosen di Gedung AH menggunakan QR Code dan dibangun dengan basis android. Aplikasi terhubung ke server dengan memanfaatkan jaringan internet di Gedung AH tiap lantai. Uji fungsionalitas pada aplikasi berjalan dengan baik, hasil pengujian scan QR Code berjalan dengan baik, namun pada android versi 6.0 membutuhkan waktu untuk scan $Q R$ Code pada aplikasi. Hasil pengujian $Q o S$ (Quality of Service) kualitas layanan yang meliputi delay, troughput, dan packet loss menggunakan sofware wireshark. Delay tertinggi ada pada saat 7 user login. Throughput yang paling baik yaitu saat 6 user mengakses aplikasi. Packet loss memiliki indeks 3 yaitu bagus.

\section{REFERENSI}

[1] F. Adikara, "Analisis Dan Perancangan Sistem Absensi Berbasis Global Positioning System ( Gps ) Pada Android 4.x," Semin. Nas. Teknol. Inf., pp. 4-9, 2013.

[2] Q. Aini, Y. I. Graha, and S. R. Zuliana, "Penerapan Absensi QRCode Mahasiswa Bimbingan Belajar pada Website berbasis YII Framework," Sisfotenika, vol. 7, no. 2, p. 207, 2017.

[3] D. Kusumayanti, "Perancangan Monitoring Kehadiran Dosen Berbasis QR CODE dan GPS," Jurnal, vol. 4, no. 2, pp. 5-37, 2016.

[4] L.Labolo, "Implementasi QRCode Untuk Absensi Perkuliahan Mahasiswa Berbasis Paperless Office," $J$. Inform. Upgris, vol. 5, no. 1, pp. 1-4, 2019.

[5] E. Rahmat et al., "Menggunakan Qr Code Reader Berbasis Android ( Studi Kasus : Fakultas Ilmu Komputer Jurusan Sistem Informasi Unsri )," Repos. Univ. Sriwij., pp. 45$50,2016$. 